\title{
Address extreme violence in Central African Republic now: MSF
}

$\mathrm{T}$ he Central African Republic's deep and extremely violent sectarian crisis has been effectively abandoned by the international community, reports Médecins Sans Frontières (MSF), which has provided health services in the country since 1998 .

"I've never seen such a high level of violence," said Dr. Joanne Liu, MSF international president at a Feb. 11 media teleconference. "This needs to be addressed now." The Montréal, Quebec physician criticized the "shocking lack of engagement and mobilization" from political leaders in the United Nations (UN) Security Council, and the limited response from African countries and the African Union to the crisis in the Central African Republic (CAR).

As of mid-February, close to 100000 Muslims had fled the country, primarily to neighbouring Chad and Cameroon; another 900000 to 1 million were internally displaced.

"The Muslim population is much more targeted right now," said Liu, who recently visited CAR, where she was head of mission in 2012. "They cannot move freely and a lot decide to flee." Among these were MSF's four Muslim staff in Bangui, CAR's capital. After they left, their houses were destroyed.

Liu says there has been a lot of dis- cussion on how to qualify what's going on, but she says it isn't genocide. "No one is encouraging people to attack their neighbours," she said.

While the death toll is unknown, stories of atrocities, such as lynching and drowning, are emerging. A Feb. 7 online video shows the brutal mob-slaying of a Muslim man who tumbled from an overcrowded truck while fleeing.

International aid has ramped up. As of Feb. 20, there were 5500 peacekeepers from the African Union (4000) and France (1500). In addition, the European Union has promsed to send 500 soldiers and France said it would send another 400 to its former colony.

UN Secretary-General Ban Ki-moon told the Security Council on Feb. 14 that the UN must live up to the promises to "act swiftly and robustly in the face of such bloodshed." In December, the UN upped CAR to a level 3 world emergency, the highest level.

"We had a lot of hope for fast-track aid," says Liu. "This has not materialized in the field."

"This is a huge failure of protection and assistance," adds MSF Canada Executive Director, Dr. Stephen Cornish, who visited CAR Jan. 7-15. "We're hearing great words coming from many places, but not seeing the action on the street."

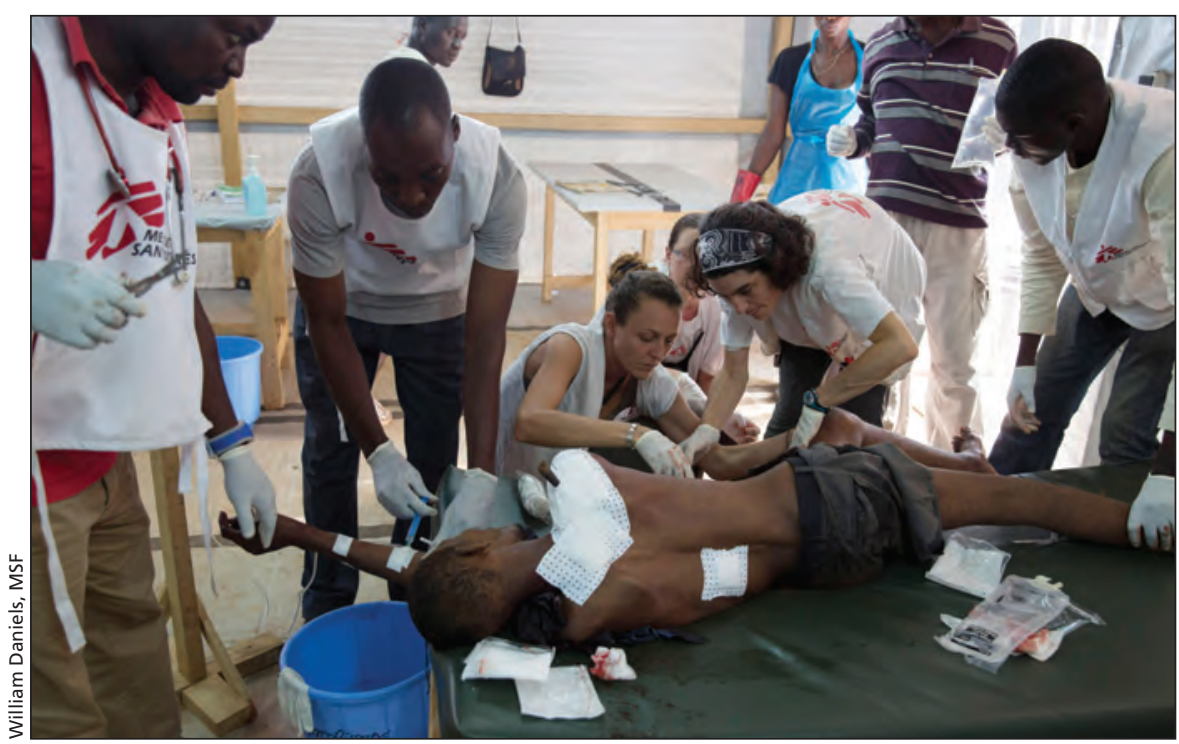

MSF medical staff treat a man in M'poko airport camp who was hit by an arrow. Combatants often use homemade weapons like axes, machetes and clubs with spikes. 


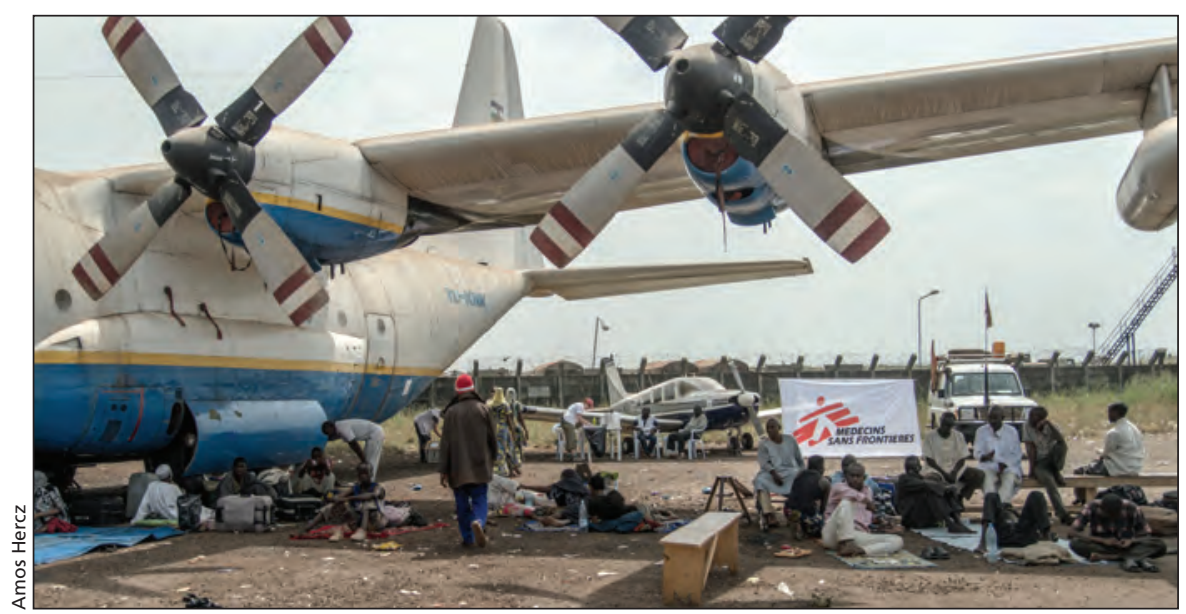

Across the tarmac from the Christian camp at M'poko airport, Muslims await transportation out of the country, primarily to Chad. The site is littered with defunct aircraft, people camped out with their luggage and clumps of human feces frying on the asphalt.

"We're a witness to this. This is our responsibility, to speak out."

About $80 \%$ of CAR's 4.6-million residents are Christian, with a sizeable Muslim population concentrated in the longmarginalized north near the borders of Sudan and Chad. The Muslim people's grievances are political and economic, not religious, but fighting has increasingly taken a sectarian tone since a coup in March 2013. At that time, an alliance of Muslim-led rebel groups from the North, called Séléka, toppled the 10-yearold government. Christian rebels, known as Anti-balaka (anti-machete), retaliated; Muslim activists hit back. Civilians have been caught in the crossfire and now some appear to be actively engaged.

The fighting escalated following street battles that began Dec. 5 between these two rebel groups in Bangui, the capital city. Since then, MSF has treated more than 3600 wounded people.

MSF has 250 international and 1800 local staff in 16 locations in CAR, and is likely the biggest humanitarian aid presence in the country. These days, its priority is treating the wounded, as well as hiding and protecting patients.

"When we're absent, our patients are at risk, which is unusual," said Liu.

As an example, she tells a story that took place in the city of Bozoum. MSF staff were called to a small courtyard where 17 people with wounds from gunshots, machetes and a grenade were hiding. "They were too scared to go to the hospital in case they were targeted again," says Liu. "Their injuries were serious, yet they were all sitting in silence, bleeding. That's how terrified people are of seeking medical care."

Given that fear, MSF has decentralized health care, delivering it through mobile clinics or health points, as well as within displaced persons' camps.

MSF reports that the extreme violence has reached unprecedented levels in early February when 9000 Muslims fled to Cameroon. Towns on the north-south axis were looted and there were rumours of village attacks, according to Heather Thomson, a nurse practitioner from Ottawa, Ontario who was MSF's medical coordinator in CAR until Jan. 21. Thomson has witnessed the aftermath of towns being burnt and seen pockets of people living in the bush.

In Bangui, some 413000 people are living in makeshift sites. About 100000 Christians are living at M'poko airport with less than four litres of water per person per day when the norm is 20 , and few sanitary facilities.

"Their conditions are appalling," says Dr. Amos Hercz, a general internist from Montréal who worked in CAR in January.

Across the tarmac is a second camp, housing a few thousand Muslims awaiting flights out of the country. They're living inside an abandoned hangar surrounded by derelict aircraft. "It's 37 degrees on the tarmac, there's no water, and landing," says Hercz. "It's a surreal environment in which to expect humans to exist." no latrines. Helicopters are taking off
Under the shade of the wing of a decommissioned Russian transport plane, Hercz and his colleagues offered primary care and treated wounds, including burns and machete lacerations. Most of the Muslim patients were injured on the way to the airport; either their convoy was attacked or they got caught in crossfire.

Hercz recalls a woman arriving with infected machete wounds across her face and burns across her torso and breasts. She was trying to breastfeed her child. The situation is "totally barbaric," says Hercz.

Before the March coup, MSF provided primary care and supported local hospitals, mainly for complicated maternity cases, and sometimes emergency and nutritional support. Staff in Bangui had quite a nice life, with sports facilities and restaurants. It was an ideal mission for training new staff. Less than a year later, it's all gone, says Hercz. Gone too are schools, sanitation and a functioning police force.

"Things are a shambles," says Hercz, who has also worked for MSF in Haiti, Ethiopia and the Republic of Congo. "It's the most unstable situation I've seen as an MSF doctor."

Not surprisingly, basic medical services, such as the provision of vaccines, are hard to come by. And that's a problem in a country where malaria remains the number one killer. CAR has malaria year-round, but during the peak rainy season, due in May, up to $90 \%$ of the population can test positive. Among the 400000 people in the city of Bossangoa, about 1000 die annually of malaria; $60 \%$ of those are under age five, says Thomson.

MSF is also seeing severe malnutrition in patients in that city, says Thomson. And that may spread as many farmers have fled. Crops are due to be planted in a month.

"It's all fallen apart," says Thomson. "With the coup, our work is gone. It's frustrating." — Barbara Sibbald, CMAJ

CMAJ 2014. DOI:10.1503/cmaj.109-4733

\section{More News online}

To read more CMAJ news articles, visit cmaj.ca/site/home/news.xhtml 